\title{
Influence of adult density on recruitment into soft sediments: a short-term in situ sublittoral experiment
}

\author{
W. A. Crowe*, A. B. Josefson, I. Svane \\ Kristineberg Marine Biological Station, S-45034 Fiskebäckskil, Sweden**
}

\begin{abstract}
Effects of different densities of the ophiuroid Amphiura filiformis and of the bivalve Abra nitida (both species separately) on initial recruitment were studied in situ in a soft-sediment environment at $25 \mathrm{~m}$ depth in the Gullmar Fjord (Sweden). Containers with known densities of residents in natural sediment, and some defaunated controls, were exposed for $9 \mathrm{~d}$ on the bottom. With both species there was a clear effect on both density and horizontal spatial distribution of recruits in the experimental containers. At high densities $\left(2400\right.$ per $\left.\mathrm{m}^{2}\right)$, A. filiformis inhibited recruitment of most taxa, whereas the effect of $A$. nitida at medium densities (1400 per $\mathrm{m}^{2}$ ) was facilitation. Both residents caused a less aggregated distribution of recruits compared with controls. The bioturbation disturbance caused by $A$. nitida seemed to have little negative effect on recruitment. It is suggested that $A$. filiformis may inhibit recruitment by ingesting settlers or newly settled juveniles.
\end{abstract}

\section{INTRODUCTION}

Soft-sedimont marine species often have patchy distributions in apparently homogeneous sediment environments (e.g. Angel \& Angel 1967, Gage \& Geekie 1973, Rosenberg 1974, Gage \& Coghill 1977). Woodin (1976) hypothesized that the boundaries observed between discrete, often age-class dominated, infaunal assemblages, and the maintenance of this discreteness, are due to interactions between established individuals and settling larvae. In succession 3 different mechanisms may be involved, namely, facilitation, tolerance and inhibition, as suggested by Connell \& Slatyer (1977). They may operate independently, or in various combinations depending on population densities and the particular species. Gallagher et al. (1983) and Whitlatch \& Zajac (1985) demonstrated experimental evidence of facilitation, Watzin (1983) and Whitlatch \& Zajac (1985) showed evidence of tolerance, and inhibition has been reported in several studies (e.g. Woodin 1976, Peterson 1979, 1982, Williams 1980, Wilson 1980, Luckenbach 1984, Elmgren et al. 1986).

\footnotetext{
- Present adress: The Shellfish Research Laboratory, Carna, County Galway, Ireland

- Address for reprint requests
}

Most experiments on adult-larval interactions have been made over relatively long periods to study successional processes and have often not distinquished between differential settlement and post-settling mortality (but see Luckenbach 1984, Watzin 1986). The latter is indeed a difficult task, but one way to study initial recruitment and reduce successional effects is to keep exposure time to a minimum.

In the experiment reported here, we have studied the effects of 2 quantitatively important species, the ophiuroid Amphiura filiformis (O. F. Müller) (hereafter refered to as Amphiura) and the bivalve Abra nitida (Müller) (hereafter Abra), on colonization of sediment in boxes exposed at a muddy-sand locality at $25 \mathrm{~m}$ depth in the Gullmar fjord, Sweden, over a $9 \mathrm{~d}$ period. The main question we posed was: Does the presence of established adults affect recruitment during a time scale of $1 \mathrm{wk}$, in terms of both the densities of the recruits and their horizontal spatial distribution?

\section{MATERIAL AND METHODS}

Two experiments were undertaken with Amphiura, one in mid July and one in mid September 1985 during the period that normally has high juvenile settlement, particularly of bivalves (Schram 1968, Muus 1973). One 
experiment was done with Abra in mid July. The experiments were undertaken at a sheltered muddysand site at $25 \mathrm{~m}$ water depth in the Gullmar Fjord approximately $200 \mathrm{~m}$ north-east of Kristineberg Marine Biological Station. This bottom has an Echinocardiumfiliformis type of assemblage (Molander 1928) in which the 2 test species are commonly found.

Sediment. Sediment $\left(1501 ; 20 \times 0.1 \mathrm{~m}^{2}\right.$ Smith-McIntyre grab samples) was collected from the experimental locality, defaunated by immersion in fresh water for $5 \mathrm{~d}$, and homogenized by sieving through a $5 \mathrm{~mm}$ mesh. Large gravel particles and macrofaunal organisms were discarded. Subsamples of the sediment were subsequently sorted, using sieves with a minimum mesh size of $0.107 \mathrm{~mm}$, to check that the sediment was azoic. No living animals were found. The sediment was then filled into 20 plastic containers $(17.8 \mathrm{~cm}$ long, $12.8 \mathrm{~cm}$ broad and $7.5 \mathrm{~cm}$ high) to $1 \mathrm{~cm}$ below the edge, and allowed to stand in running seawater for several hours prior to addition of the test animals. This water is pumped to the laboratory from $35 \mathrm{~m}$ depth close to the experimental site, and normally contains very few larvae (Granmo pers. comm.).

Test species and deployment of experimental boxes. The 2 test species (Amphiura filiformis and Abra nitida) were collected using a modified Ockelmann dredge and separated from the sediment by a $2 \mathrm{~mm}$ mesh. For A. nitida only specimens with a shell length greater than $5 \mathrm{~mm}$ were used. High and medium densities of the test species (Table 1), were established in separate containers, forming 4 replicates of each density treatment for each test species. Four containers with defaunated sediment only were used as controls.

The test species were allowed to establish in the containers for $4 \mathrm{~d}$, whilst kept in running seawater at the laboratory. Afterwards a lid was placed over each container while still submerged. The containers were then quickly (within ca $15 \mathrm{~min}$ ) transported to the experimental site and distributed on the bottom by a diver. The diver was unaware of how the boxes were related to treatments and test species. After the boxes had been placed on the sediment, the lids were removed. In both experimental runs, the containers were retrieved after $9 \mathrm{~d}$ from the sea bottom (covered by lids during transport), and immediately subsampled.

Subsampling. Subsampling of the containers was performed as follows: 8 corers of $1.8 \mathrm{~cm}$ internal diameter for Abra, and 4 corers of $3.8 \mathrm{~cm}$ internal diameter for Amphiura, were inserted in the sediment contiguously along the middle length of each container. Different core sizes were used to conform to the different sizes of the test species. The control containers were sampled with both types of corers. Sediments in the top $2 \mathrm{~cm}$, the 2 to $4 \mathrm{~cm}$ depth interval, and the remaining $2.5 \mathrm{~cm}$ of each core were retained separately in glass jars with
$5 \%$ borax buffered formalin stained with rose bengal. In addition to the subsampling, the remainder of the sediment in the containers was sieved through a $1.9 \mathrm{~mm}$ mesh and the residue was kept to observe how many of the test animals had survived the experiment and to observe if macroscopic colonists were present.

The material obtained in the top $2 \mathrm{~cm}$ of the cores was divided and sorted in 2 fractions of 0.107 to $0.178 \mathrm{~mm}$ and $>0.178 \mathrm{~mm}$, respectively. Animals were elutriated from the fine fraction, but manually sorted from the coarse fraction. In all cases animals were sorted out under a microscope at $25 \times$ magnification. Analysis of some of the cores, 4 large and 7 small ones, showed that on average $70 \%$ of the individuals were found in the top $2 \mathrm{~cm}$ of the sediment. This is also the region in which both test species would be expected to exert most influence due to their feeding behaviour. Therefore the subsequent analysis was restricted to this sediment zone.

In the first experiment with Amphiura and in the Abra experiment all 4 boxes were analysed, whereas in the second experiment with Amphiura, 3 boxes were analysed in each treatment. In the first experiment with Amphiura, 4 cores were analysed from each of the control boxes and the high density boxes. From each of the medium density boxes of this experiment, and from each of all boxes in the second Amphiura experiment, 3 cores were analyzed. In the Abra experiment 8 cores were analyzed from each of the boxes in the control and the high density treatment, whereas 4 cores were analyzed from each of the boxes from the medium density treatment. Whenever fewer samples were analyzed than the number taken, they were chosen using random numbers from the total number available.

In the analysis of the medium density treatment of Amphiura in the second experiment the arenaceous foraminiferans were unfortunately not recorded.

Statistical analysis. Densities of the total and of the numerically dominant recruiting taxa, which occurred in more than $60 \%$ of the cores in each treatment, were statistically analysed for each sampling date separately, using a 1-way nested analysis of variance (SAS Institute 1982) with containers rested within treatments. The hypothesis tested was that there was no difference in recruitment between the treatments. In addition to a significance level for effects of treatments, each test yielded a significance level for the effects of individual containers within treatments, in the following called 'container effect'. Data were not transformed prior to analysis as they complied with the homoscedasticity assumption of ANOVA (Hartley's F-max test; Sokal \& Rohlf 1981). Whenever a significant treatment effect was found the differences between means for treatments were tested with the Student-NewmanKeul's test (SAS Institute 1982, Sokal \& Rohlf 1969). 
The horizontal microdistribution of the established individuals and of the colonists was investigated for several different sample sizes. The medium density treatments and the second experiment with Amphiura were excluded because too few cores were analyzed. For the established individuals whole cores were considered, while for the colonists only the top $2 \mathrm{~cm}$. The 8 cores from each Abra box were considered as 8 individual samples, then grouped 2 at a time representing 4 samples, and 4 at a time representing 2 samples. The 3 sample sizes actually sampled $2.5,5$, and $10 \times 10^{-4} \mathrm{~m}^{2}$ of sediment.

The 4 cores of each Amphiura box were considered as 4 individual samples, and 2 samples of cores grouped 2 at a time. The 2 sample sizes actually sampled 11.3 and $22.6 \times 10^{-4} \mathrm{~m}^{2}$. The coefficients of dispersion (variance/mean ratios) were calculated for different block sizes for both the Abra and Amphiura treatments.

The $95 \%$ limits of the Poisson expectation were calculated. To show the limits between aggregation and random, and between random and even distributions (Angel \& Angel 1967) the Monte Carlo method was applied as described in Gage \& Coghill (1977).

\section{RESULTS}

One d after the test species (Amphiura filiformis and Abra nitida) were set up in the experimental containers at the laboratory, the entire sediment surfaces were reworked. Containers with Abra were clearly dis- tinguishable from containers with Amphiura. The former had the characteristic feeding traces and heaps of pseudofaeces and faecal pellets, while the ones with Amphiura showed mounds around the openings for the arms. The test species were exhibiting feeding behaviour. The mean survival levels of the test animals after $9 \mathrm{~d}$ on the bottom were relatively high (Table 1 ). In general 80 to $100 \%$ of the individuals were recovered alive on termination of the experiments. No significant immigration of macrofauna (colonists larger than $2 \mathrm{~mm}$ ) into the containers was observed (Table 1).

\section{Effects of residents on recruitment}

The effects of residents on initial recruitment of the total fauna and of the common colonizing taxa are shown graphically in Fig. 1 to 3 .

Amphiura treatment: 1st experiment (Fig.1). The treatments with Amphiura in the first experiment showed a highly significant effect on the total number of colonizers $(p<0.001$ ). The medium density showed a increase in recruitment relative to the control, while the high density treatment showed a decrease. This pattern was consistent for 2 of the individual groups, namely Nematoda and Arachnida. An additional 2 groups, Vermes and Copepoda, showed a decrease in the high density treatment relative to the control. Kinorhyncha showed higher recruitment in the medium density treatment relative to both control and high density treatment and Foraminifera showed higher recruitment in both treatments compared to the

Table 1. Initial density and survival of the test animals Abra nitida and Amphiura filiformis, and mean number of macrofaunal colonists into sediment containers after $9 \mathrm{~d}$ at $25 \mathrm{~m}$ depth. Expt I was done in July and Expt II in September 1985. 'Medium' and 'High' refer to the 2 density treatments

\begin{tabular}{|c|c|c|c|c|c|c|}
\hline & \multicolumn{2}{|c|}{ Control } & \multicolumn{2}{|c|}{ Medium } & \multicolumn{2}{|c|}{ High } \\
\hline & Expt I & Expt II & Expt I & Expt II & Expt I & Expt II \\
\hline \multicolumn{7}{|c|}{ Initial number of individuals } \\
\hline Abra per container & 0 & - & 33 & - & 66 & - \\
\hline per $\mathrm{m}^{2}$ & 0 & - & 1447 & - & 2895 & - \\
\hline \multirow{2}{*}{$\begin{array}{cl}\text { Amphiura } & \text { per container } \\
& \text { per } \mathrm{m}^{2}\end{array}$} & 0 & 0 & 28 & 28 & 55 & 55 \\
\hline & 0 & 0 & 1228 & 1228 & 2412 & 2412 \\
\hline \multicolumn{7}{|c|}{ Percent survival at termination } \\
\hline Abra \% & - & - & 87.9 & - & 74.6 & - \\
\hline $\mathrm{SD}$ & - & - & 2.0 & - & 24.7 & - \\
\hline Amphiura $\%$ & - & - & 97.3 & 87.9 & 97.8 & 96.4 \\
\hline $\mathrm{SD}$ & - & - & 5.4 & 3.9 & 2.3 & 6.3 \\
\hline \multicolumn{7}{|c|}{ Macrofaunal colonists $>2 \mathrm{~mm}$ (no. per container) } \\
\hline Control & 2 & 4.7 & - & - & - & - \\
\hline SD & 1.4 & 2.5 & - & - & - & - \\
\hline Abra treatment & - & - & 2 & - & 1.5 & - \\
\hline $\mathrm{SD}$ & - & - & 4 & - & 1.9 & - \\
\hline Amphiura treatment & - & - & 4 & 1.7 & 0.2 & 2.3 \\
\hline $\mathrm{SD}$ & - & - & 2.7 & 2.1 & 1.0 & 1.5 \\
\hline
\end{tabular}



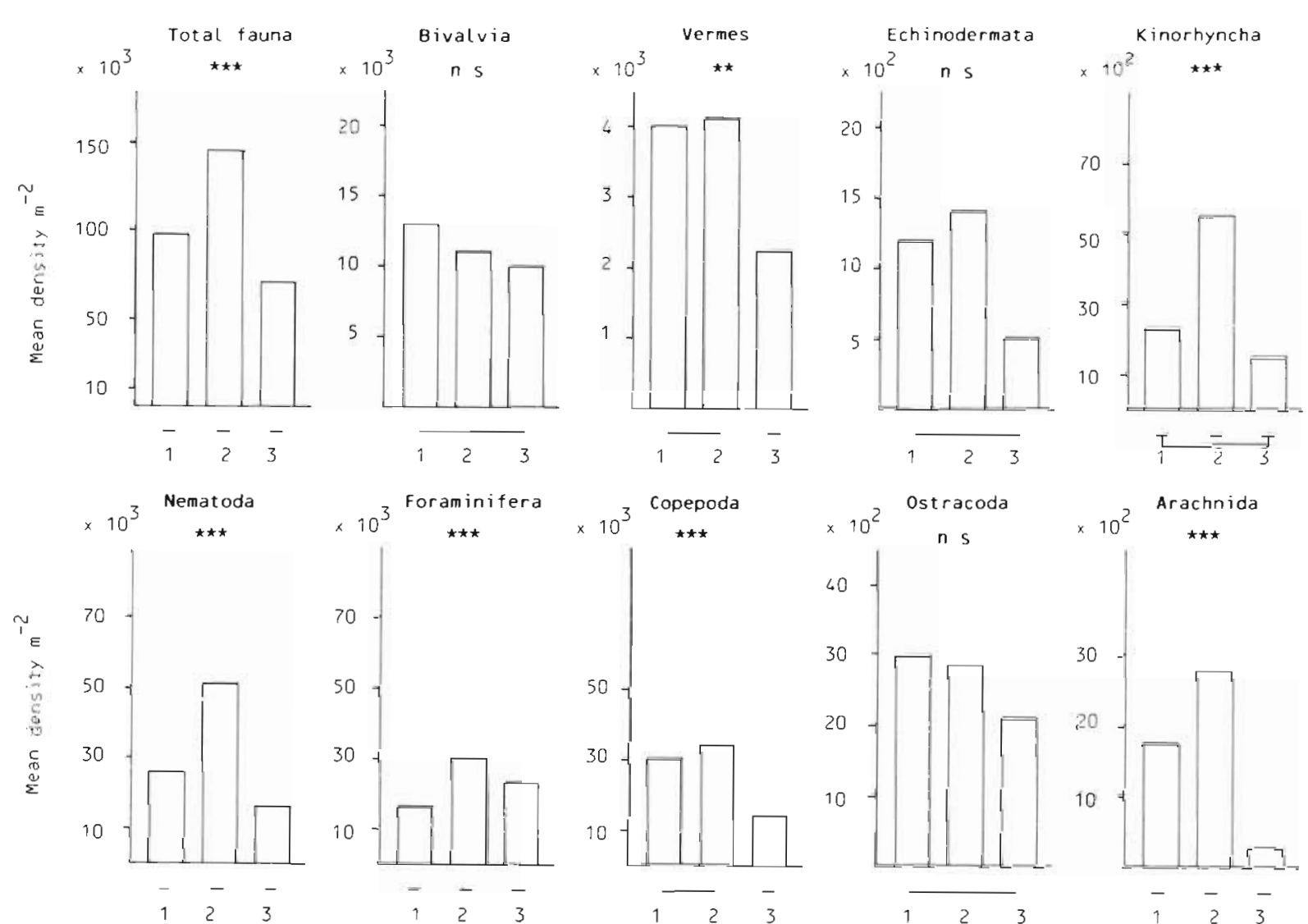

Fig. 1. Histograms showing mean densities of individuals of 10 faunal groups recruiting into sediment-boxes with residents of Amphiura filiformis, after $9 \mathrm{~d}$ on the sea bottom in mid July (Expt I). Treatments: $1=$ control; $2=$ medium density; $3=$ high density. Significance levels are given for effects of treatment using a 1-way nested ANOVA ( ${ }^{\cdots} p<0.001 ; \cdots p<0.01$; $\cdot p<0.05 ; n s, p>0.05$ ). Differences between means for treatments were tested with the Student Newman Keul's test, and commonly underlined bars are not statistically different $(p>0.05)$

control. Bivalvia, Ostracoda and Echinodermata showed no significant differences in ANOVA $(p>0.05)$. Except for Vermes, no significant effects caused by the containers were found $(p>0.05)$.

Amphiura treatment: 2nd experiment (Fig.2). The treatments with Amphiura in the second experiment also showed a very significant $(p<0.01)$ effect on the total number of recruits. As in the first experiment the high density treatment showed a significant decrease in recruitment relative to the control, whereas the medium density treatment did not differ significantly from the control. Bivalvia, Copepoda (mainly harpacticoids) and Nematoda showed lower recruitment in both high and medium density treatments compared to the control. Foraminifera showed a higher recruitment in the medium density treatment compared to both control and high density treatment. Other groups Vermes, Echinodermata, Kinorhyncha, Ostracoda and Arachnida - did not show a significant difference in ANOVA $(p>0.05)$. Except for Foraminifera, no effects caused by the containers were found $(p>0.05)$.
Abra treatment: (1 experiment only) (Fig.3). Abra densities had a highly significant effect on the total number of recruits $(p<0.001)$. The medium density treatment showed significantly higher recruitrnent than the control and the high density treatment, while the high density treatment was slightly higher than the control. An identical pattern was shown by Nematoda, whereas Bivalvia, Foraminifera and Copepoda showed a higher recruitment in the medium density treatment compared to both the control and the high density treatment. Vermes did not show a significant difference in ANOVA $(p>0.05)$. There were clear effects caused by the containers for all taxa except Bivalvia and Vermes $(\mathrm{p}<0.05)$.

\section{Effects of residents on the microdistribution of recruits}

The dispersion of the total number of residents and colonizers from the 1st experiment is depicted in Fig. 4 $\& 5$, respectively. The coefficients of dispersion were 

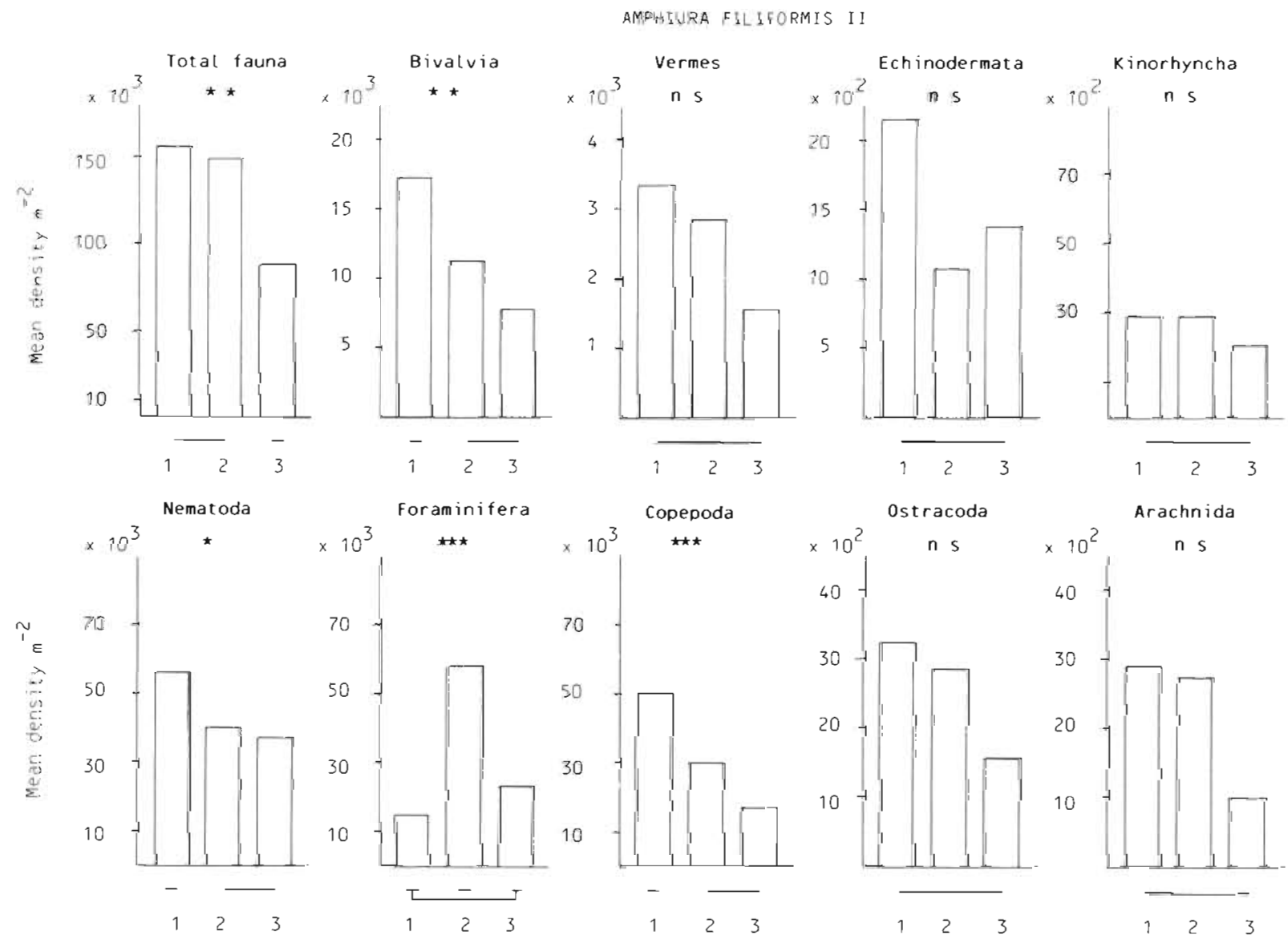

Fig. 2. Histograms showing mean densities of individuals of 10 faunal groups recruiting into sediment-boxes with residents of Amphinra filiformis after $9 \mathrm{~d}$ on the sea bottom in mid September (Expt II). For explanation see Fig. 1 legend

calculated for different combinations of cores (i.e. sample sizes) within the containers. Comparisons were made only between the high density treatment and the control for the invading taxa, and between the high and medium densities for the resident test species. Both species of residents had a distribution in the containers that showed little deviation from random, the deviation being slightly greater at high densities for Abra nitida (Fig. 4). However, the invading recruits in both treatments and controls showed a distribution which deviated from random towards clumping. In the Abra treatments the distribution of invading taxa in the controls deviated more from random towards clumping than in the high density treatment (Fig.5). In the Amphiura treatments the distributions of recruits showed a similar pattern, although with greater overlap (Fig. 5).

For the small core sizes used in the Abra treatments $(1.8 \mathrm{~cm}$ internal diameter) the amount of aggregation noted among the colonizing individuals decreased with increasing block size, both in the control containers and the Abra high density boxes (Fig. 5). It can be seen in the graph that the distribution of the fauna was random, or close to it, at block sizes of 4 combined cores (i.e. with a linear dimension of $\mathrm{ca} 8 \mathrm{~cm}$ ). For the larger core sizes of the Amphiura treatments $(3.8 \mathrm{~cm}$ internal diameter) in the high density containers the amount of aggregation observed among the invading taxa decreased with the increase in block size from considering cores singly to combined 2 at a time (i.e. from a block size of approximately 4 to one of $8 \mathrm{~cm}$ ). However, an increase in aggregation was noted in the control treatments at the larger block size (Fig. 5).

\section{DISCUSSION}

Of the 3 models of succession proposed by Connell \& Slatyer (1977), the inhibition model best explains the majority of cases of adult-larval interactions in high density soft-sediment communities. This view holds that infaunal adults have a deleterious effect on the recruitment and survival of larvae and juveniles. This effect has in most cases been attributed to predation either by meiofauna (Thorson 1966, Watzin 1983, 1986), deposit-feeding amphipods (Segerstråle 1962, Oliver et al. 1982, Elmgren et al. 1986), bivalves 

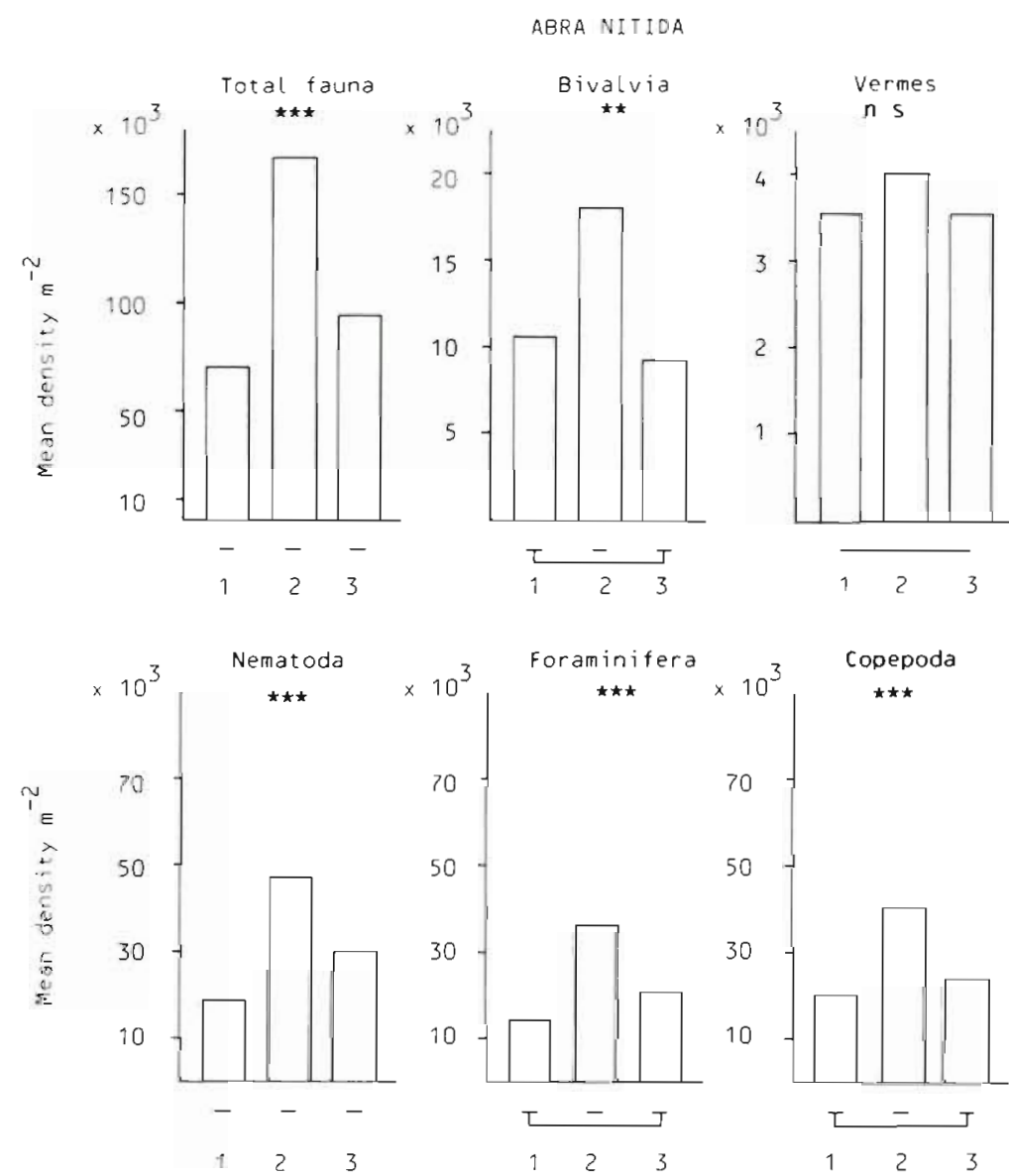

Fig. 3. Histograms showing mean densities of individuals of 6 faunal groups recruiting into sediment-boxes with residents of Abra nitida after $9 \mathrm{~d}$ on the sea bottom in mid July. For explanation see Fig. 1 legend

(Mileikovski 1974, Williams 1980) and polychaetes (Wilson 1980) or crustaceans (Peterson 1977). Inhibition may also be caused by active behavioural avoidance (Woodin 1985). Woodin (1976) and Peterson (1979) suggested that inhibition was the most important mechanism of succession in soft bottom communities and predicted this to occur only in areas with high densities of residents. However, Gallagher et al. (1983) found that tube builders may facilitate recruitment. They suggested that the mechanism was active habitat-selection by the larvae and juveniles, probably keyed to the small-scale alterations caused by the tubes. On the other hand settlement may be a passive process caused by changed hydrodynamics due to the tube-structures (Eckman 1983, 1987) although not generally applicable (Peterson 1986).

The experiments reported here do not distinguish between the mechanisms behind the observed effects on colonization but it is likely that the residents played at least a dual role. Firstly, when feeding they may reduce survival of the invaders and secondly, they may change the physical and chemical environment (Peterson 1979). Settlement of larvae and immigration of meiofauna may occur either by passive dispersal or by active selection. Active selection may involve a number of variables such as substratum quality, chemical cues and modification of the physical environment. The presence of adults undoubtedly changes the quality of the chemical and physical properties of the sediment and in the case of Amphiura also in the near-bottom water.

Our results show that high densities of Amphiura inhibit recruitment into the experimental boxes. This pattern was consistent in both the first and the second experiments and includes both the larval settlers (Bivalvia, Echinodermata, Vermes), as well as the meiofaunal groups representing immigrating species. In the medium density treatments this pattern was less clear (Fig. $1 \& 2$ ).

The 'high density' used in our experiments (2412 ind $\mathrm{m}^{-2}$ ) is similar to those recorded in the southern Skagerrak and the northern Kattegatt by Josefson (1986), and lower than those reported for Saltkällefjord by Rosenberg \& Möller (1979) where densities of about 4000 ind $\mathrm{m}^{-2}$ were recorded.

When feeding, Amphiura holds 3 or 4 of its arms up into the current flow with a rheotactic response to current direction, trapping both non-living particulate suspended matter and living phytoplankton (Buchanan 1964, Ockelmann \& Muus 1978). Hunt (1925) found bottom material detritus, foraminiferans and occasion- 


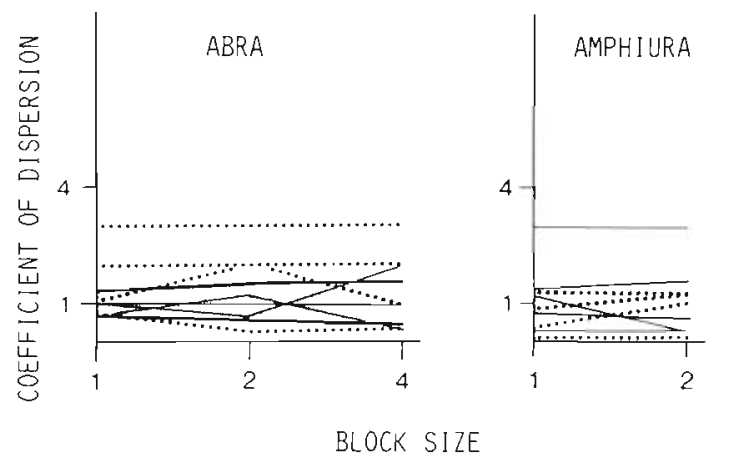

Fig. 4. Coefficients of dispersion for residents in Abra and Amphiura treatments at various combinations of cores (block sizes) from containers with medium (solid lines) and high (dotted lines) density treatments. Shaded area denotes interval of random expectation

ally small molluscs and worms in the guts of Amphiura. The general consensus, however, is that poorly selected bottom detritus constitutes most of the food although occasionally small animals may be ingested (Blegvad 1914, Buchanan 1964). The findings of our experiments may readily be interpreted in the light of the feeding behaviour of Amphiura. Thorson (1958) is of the opinion that newly settled larvae may suffer greatly from the feeding activities of Amphiura. Our experiments suggest that this may be the case, at least when the density of this species is high enough, and this is in agreement with Woodin $(1976,1979)$ who

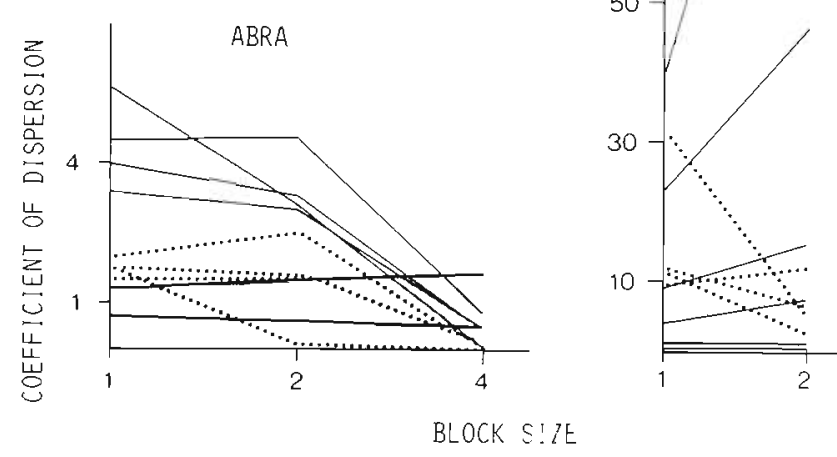

Fig. 5. Coefficients of dispersion for total number of recruits in control containers (solid lines) and containers with high densities of Abra and Amphiura (dotted lines). Shaded area denotes interval of random expectation predicted inhibition to predominate in high density assemblages. Another possibility is that colonizers actively avoided containers with Amphiura due to some chemical agent emitted by this species (e.g. Woodin 1985). If so, unless dosage-dependent, a similar reaction may be expected also in the medium density treatments. However, no such effect was found. It therefore seems more likely that the inhibitory effect is caused by the feeding activities of Amphiura. Another factor of possible importance is the conditioning of the sediment caused by the feeding activity of the residents. A bioturbated sediment may include cues that attract invaders. This may be the reason why the medium density treatments in some cases seemed to facilitate rather than inhibit recruitment. The controls had sediment surfaces virtually without traces of animals. In the high density treatment the detrimental effect of feeding may be strong enough to counterbalance such a conditioning effect and, in the case of Amphiura, actually inhibit colonization.

In the experiment with Abra a pattern of facilitation at medium densities was found when considering total fauna (Fig. 3). Of the 2 test species, Abra most likely disturbs the sediment surface more. Therefore, our results are unexpected if impact of bioturbation were the important inhibiting factor (Brenchley 1981, Wilson 1981).

Josefson (1982) reported densities of Abra nitida up to 2000 ind $\mathrm{m}^{-2}$ in the Skagerrak. Here we used densities of 1447 and 2895 ind $\mathrm{m}^{-2}$ in the medium and high density treatments, respectively. In both treatments $83 \%$ of the adult $A b r a$ were recovered in the top $2 \mathrm{~cm}$ of the sediment, $17 \%$ in the 2 to $4 \mathrm{~cm}$ horizon and none below this. In aquaria, Abra were found most commonly between 2.5 and $4.0 \mathrm{~cm}$ depth with a low correlation between shell length and burrowing depth (Wikander 1980). However, Abra takes all its sediment from the top few millimeters of the sediment, and deposits feacal pellets and pseudofaeces in heaps on the sediment surface (Wikander 1980). Thus, colonizing species are most likely to be present within the feeding region of Abra, although some worms may burrow deeper (Woodin 1974). At the end of our experiment, as well as before exposure on the bottom, there was visual evidence of considerable sediment reworking. Assuming that the estimated reworking capacity of Abra, determined by Wikander (1981) under laboratory conditions, approximates conditions in the field, then all the top $5 \mathrm{~mm}$ of the sediment would have passed through the mantle cavity of $A b r a$ at least once in the medium density treatment of our experiment, and possibly 2 or 3 times in the high density treatment. Of this sediment only a minor portion (probably $<5 \%$ ) is likely to have passed through the digestive system of Abra (Wikander 1981). Thus, Abra is less likely to exert 
an effect by ingesting colonists. However, it is possible that passage through the mantle cavity of Abra represents a mortality agent for potential colonizers and decreases the chance of successful establishment in the bottom substratum. According to Mileikovski (1974), larvae ingested by deposit-feeders have low chances of survival, whereas Hylleberg \& Galucci (1975) claimed no such effect on bivalve spat.

In addition to the effects discussed, the residents seemed to affect the horizontal distribution of the invaders. The distribution of the invaders in the controls was less random than in the high density treatments for both species (Fig. 5). This is in agreement with the observation that the residents themselves showed a nearly random distribution (Fig.4). Apparently the residents prevented aggregation of invaders in the containers, but the mechanism is unknown.

Acknowledgements. This work was financed by a scholarship from the Swedish Institute to $W$. A. Crowe and was performed with the aid of the staff at the Kristineberg Marine Biological Station, which is hereby acknowledged. Financial aid was also given by the National Swedish Environment Protection Board (A. B. Josefson), and the National Swedish Research Council (I. Svane, Contract no: B-BU-8526-102). Anonymous referees improved the manuscript.

\section{LITERATURE CITED}

Angel, H. H., Angel, M. V. (1967). Distribution pattern analysis in a marine benthic community. Helgoländer wiss Meeresunters. 15: 445-454

Blegvad, H. (1914). Food and conditions of nourishment among the communities of invertebrate animals found on or in the sea bottom in Danish water. Rep. Dan. Biol. Stn 22: $41-78$

Brenchley, G. A. (1981). Disturbance and community structure: an experimental study of bioturbation in marine softbottom environments. J. mar. Res. 39: 767-790

Buchanan, J. B. (1964). A comparative study of some features of the biology of Amphiura filiformis and Amphiura chiajei (Ophiuroidea) considered in relation to their distribution. J. mar. biol. Ass. U.K. 44:565-576

Connell, J. H., Slatyer, R. O. (1977). Mechanisms of succession in natural communities and their role in community stability and organization. Am. Nat. 111: 1119-1144

Eckman, J.E. (1983). Hydrodynamic processes affecting benthic recruitment. Limnol. Oceanogr. 28: 241-257

Eckman, J. E. (1987). The role of hydrodynamics in recruitment, growth, and survival of Argopecten irradians (L.) and Anomia simplex (D'Orbigny) within eelgrass meadows. J. exp. mar. Biol. Ecol. 106: 165-191

Elmgren, R., Ankar, S., Marteleur, B., Ejdung, G. (1986). Adult interference with postlarvae in soft sediments: the Pontoporeia-Macoma example. Ecology 67: 827-836

Gage, J. D., Coghill, G. C. (1977). Studies on the dispersion patterns of Scottish Sea Loch benthos from contiguous core transects. In: Coull, B. C. (ed.) Ecology of marine benthos. Univ. South Carolina Press, Columbia, p. 319-337

Gage, J. D., Geekie, A. D. (1973). Community structure of the benthos in Scottish Sea Lochs. III. Further studies on patchiness. Mar. Biol. 20: 89-100
Gallagher, E. D., Jumars, P. A., Trueblood, D. D. (1983) Facilitation of soft bottom benthic succession by tube builders. Ecology 64: 1200-1216

Hunt, O. D. (1925). The food of bottom fauna of the Plymouth fishing grounds. J. mar. biol. Ass. U.K. 13: 560-599

Hylleberg, J, Gallucci, V. F. (1975). Selectivity in feeding by the deposit feeding bivalve Macoma nasuta. Mar. Biol. 32: $167-178$

Josefson, A. B. (1982). Regulation of population size, growth, and production of a deposit-feeding bivalve: a long-term field study of three deep-water populations off the Swedish west coast. J. exp. mar. Biol. Ecol. 59: 125-150

Josefson, A. B. (1986). Övervakning av mjukbottenfauna längs Sveriges västkust. Naturvårdsverket Rapport 3247 (Swedish; English summary)

Luckenbach, M. W. (1984). Settlement and early post-settlement survival in the recruitment of Mulinia lateralis (Bivalvia). Mar. Ecol. Prog. Ser. 17: 245-250

Mileikovski, S. A. (1974). On predation of pelagic larvae and early juveniles of marine bottom invertebrates and their passing alive through their predators. Mar. Biol. 26: 303-311

Molander, A. R. (1928). Animal communities on soft bottom areas in the Gullmar Fjord. Kristinebergs Zoologiska Sta. tion $1877-1927$, No 2: $1-90$

Muus, K. (1973). Settling, growth and mortality of young bivalves in the Öresund. Ophelia 12: 79-116

Ockelmann, K. W., Muus, K. (1978). The biology, ecology and behaviour of the bivalve Mysella bidentata (Montagu) Ophelia 17: 1-93

Oliver, J. S., Oakden, J. M., Slattery, P. N. (1982). Phoxocephalid amphipod crustaceans as predators on larvae and juveniles in marine soft-bottom communities. Mar. Ecol. Prog. Ser. 7: 179-184

Peterson, C. H. (1977). Competitive organization of the soft bottom macrobenthic communities of Southern California Lagoons. Mar. Biol. 43: 343-359

Peterson, C. H. (1979). Predation, competitive exclusion, and diversity in the soft-sediment benthic communities of estuaries and lagoons. In: Livingston, R. J. (ed.) Ecological processes in coastal and marine systems. Plenum Press, New York, p. 233-264

Peterson, C. H. (1982). The importance of predation and intraand interspecific competition in the population biology of two infaunal suspension-feeding bivalves, Protothaca staminea and Chione undatella. Ecol. Monogr. 52: $437-475$

Peterson, C. H. (1986). Enhancement of Mercenaria mercenaria densities in seagrass beds: is pattern fixed during settlement season or altered by subsequent differential survival? Limnol. Oceanogr. 31: 200- 205

Rosenberg, R. (1974). Spatial dispersion of an estuarine benthic faunal community. J. exp. mar. Biol. Ecol. 15 : $69-80$

Rosenberg, R., Möller, P. (1979). Salinity stratified benthic macrofaunal communities and long-term monitoring along the West Coast of Sweden. J. exp. Mar. Biol. Ecol. 37: $175-203$

SAS Institute Inc. (1982). SAS user's guide: statistics, 1982 edn. SAS Institute Inc., Cary, North Carolina, USA

Schram, T. A. (1968). Studies on the meroplankton in the inner Oslofjord. I. Composition of the plankton at Nakkholmen during a whole year. Ophelia 5: 221-243

Segerstråle, S. G. (1962). Investigations on Baltic populations of the bivalve Macoma baltica (L.). Part II. What are the reasons for the periodic failure of recruitment and scarcity of Macoma in the deeper waters of the inner Baltic? Commentat. Biol. 24: 1-26 
Sokal, R. R., Rohlf, F. J. (1969). Biometry, 1st edn. W. H. Freeman \& Co., San Francisco

Sokal, R. R., Rohlf, F. J. (1981). Biometry, 2nd edn. W. H. Freeman \& Co., San Francisco

Thorson, G. (1958). Parallel level-bottom communities, their temperature adaption, and their 'balance' between predators and food animals. In: Buzzati-Traverso, A. A. (ed.) Perspectives in marine biology. Univ. California Press, Berkeley, p. $67-86$

Thorson, G. (1966). Some factors influencing the recruitment and establishment of marine benthic communities. Neth J. Sea Res. 3: 267-293

Watzin, M. C. (1983). The effects of meiofauna on settling macrofauna: meiofauna may structure macrofaunal communities. Oecologia 59: 163-166

Watzin, M. C. (1986). Larval settlement into marine soft-sediment systems: interactions with the meiofauna. J. exp. mar. Biol. Ecol. 98: 65-113

Whitlatch, R. B., Zajac, R. N. (1985). Biotic interactions among estuarine infaunal opportunistic species. Mar. Ecol. Prog. Ser. 21: 299-311

Wikander, P. B. (1980). Biometry and behaviour in Abra nitida (Mueller) and Abra longicallus (Scacchi) (Bivalvia, Tellinacea). Sarsia 65: 255-268

Wikander, P. B. (1981). Quantitative aspects of deposit feed- ing in Abra nitida (Mueller) and Abra longicallus (Scacchi) (Bivalvia, Tellinacea). Sarsia 66: 35-48

Williams, J. G. (1980). The influence of adults on the settlement of spat of the clam, Tapes japonica. J. mar. Res. 38: 729-741

Wilson, J.., W. H. (1980). A laboratory investigation of the effect of a terebellid polychaete on the survivorship of nereid polychaete larvae. J. exp. mar. Biol. Ecol. 46: 73-80

Wilson, Jr., W. H. (1981). Sediment-mediated interactions in a densely populated infaunal assemblage: the effects of the polychaete Abarenicola pacifica. J. mar. Res. 39: 735-748

Woodin, S. A. (1974). Polychaete abundance patterns in a marine soft sediment environment: the importance of biological interactions. Ecol. Monogr. 44: 171-187

Woodin, S. A. (1976). Adult-larval interactions in dense infaunal assemblages: patterns of abundance. J. mar. Res. 34: $25-41$

Woodin, S. A. (1979). Settlement phenomena: the significance of functional groups. In: Stancyk, S. E. (ed.) Reproductive ecology of marine invertebrates. Belle W. Baruch Library in Marine Science No. 9, Univ. South Carolina Press, Columbia, p. 99-106

Woodin, S. A. (1985). Effects of defaecation by arenicolid polychaete adults on spionid polychaete juveniles in field experiments: selective settlement or differential mortality. J. exp. mar. Biol. Ecol. 87: 119-132

This article was submitted to the editor; it was accepted for printing on September 10, 1987 